\title{
The multifaceted Diels-Alder reactivity of 4,6-dinitrobenzofuroxan and 4,6-dinitrobenzofurazan towards isoprene and 2,3-dimethylbutadiene
}

\author{
Régis Goumont, ${ }^{* a}$ Muriel Sebban, ${ }^{a}$ Jérome Marrot, ${ }^{b}$ and François Terrier*a \\ ${ }^{a}$ Laboratoire SIRCOB, UMR CNRS 8086, Institut Lavoisier, Université de Versailles; \\ 45, Avenue des Etats-Unis; 78035 Versailles Cedex, France \\ ${ }^{b}$ Laboratoire IREM, UMR CNRS CO173, Institut Lavoisier, Université de Versailles; 45, \\ avenue des Etats-Unis; 78035 Versailles Cedex, France
}

E-mail:terrier@chimie.uvsq.fr

\begin{abstract}
Dedicated to Professor Makosza on the occasion of his $70^{\text {th }}$ birthday in recognition of his many contributions to the chemistry of nitroactivated aromatics and heteroaromatics
\end{abstract}

(received 27 Oct 03; accepted 26 Dec 03; published on the web 07 Jan 04)

\begin{abstract}
The reactions of 4,6-dinitrobenzofuroxan (DNBF) and 4,6-dinitrobenzofurazan (DNBZ) with isoprene and 2,3-dimethylbutadiene afford stable diadducts (10a-d), which are shown to result from two consecutive and highly stereoselective normal electron-demand Diels-Alder (NEDDA) condensations. These condensations involve the two nitro-activated double bonds of DNBF and DNBZ as the dienophile contributors. Evidence that the first molecule of diene adds to the $\mathrm{C}_{6}-\mathrm{C}_{7}$ rather than the $\mathrm{C}_{4}-\mathrm{C}_{5}$ double bond has been obtained through ${ }^{15} \mathrm{~N}$-labelling of the 4- $\mathrm{NO}_{2}$ group of DNBF and NMR characterization of the corresponding short lived monoadducts (9a-d). An unprecedented finding is that these monoadducts undergo subsequent addition of the second molecule of diene to give not only the stable "symmetrical" NEDDA-NEDDA diadducts 10a-d but also the "unsymmetrical" diadducts 11a-d resulting from inverse electron demand DielsAlder (IEDDA) condensations in which the $\mathrm{O}_{4} \mathrm{~N}_{4} \mathrm{C}_{4} \mathrm{C}_{5}$ fragment of $\mathbf{9 a - d}$ acts as a heterodiene moiety. Although 11a-d are not thermodynamically stable, undergoing a slow conversion to 10a$\mathbf{d}$ in solution, a pure sample of the isoprene-DNBF NEDDA-IEDDA diadduct 11a could be isolated as a crystalline solid and characterized by X-Ray crystallography.
\end{abstract}

Keywords: Diels-Alder cycloadditions, mono- and di-adducts, nitrobenzofuroxans, thermodynamic and kinetic control 


\section{Introduction}

In the last two decades, much evidence has been accumulated showing that nitro-substituted 2,1,3-benzoxadiazoles and related 1-oxides, commonly referred to as nitrobenzofurazans and nitrobenzofuroxans, respectively, are neutral $10-\pi$ electron-deficient heteroaromatic substrates which, in many processes exhibit extremely high electrophilic character. ${ }^{1-9}$ As a best illustration for this behavior is the finding that 4,6-dinitrobenzofuroxan (DNBF), the reference compound in this family, behaves as a stronger electrophile than the 4-nitrobenzenediazonium cation. ${ }^{10}$ This has led to many analytical applications with the use of DNBF as a suitable probe to assess the reactivity of extremely weak carbon nucleophiles such as benzenoid aromatic or $\pi$-excessive heteroaromatics with large negative pKa values, e.g. 1,3-dimethoxybenzene (pKa = -9), ${ }^{10 c} 3$ methoxythiophene $(\mathrm{pKa}=-6.5)^{10 \mathrm{~b}}$ or aniline $(\mathrm{pKa}=-6) .{ }^{4 \mathrm{~b}}$ In all of the above processes, covalent addition of the carbon nucleophile takes place at C-7 of the carbocyclic ring of DNBF to give stable anionic $\sigma$-complexes, e.g. $\mathbf{1}$ or $\mathbf{2}$, as it also does in all reported interactions of DNBF with oxygen, sulfur or nitrogen nucleophiles. ${ }^{1}$ Also, it has been recognized that the ease of covalent nucleophilic addition to the carbocyclic ring is responsible for the inhibitory effects exerted by some mono-nitrobenzofuroxans and benzofurazans on the biosynthesis of nucleic acid and protein in leucocytes, and the observed activity of the compounds against leukaemia. ${ }^{6}$

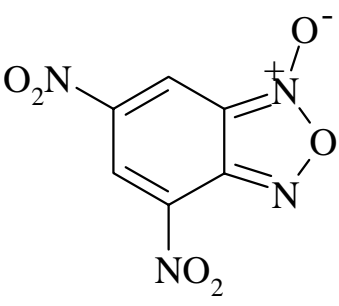

DNBF

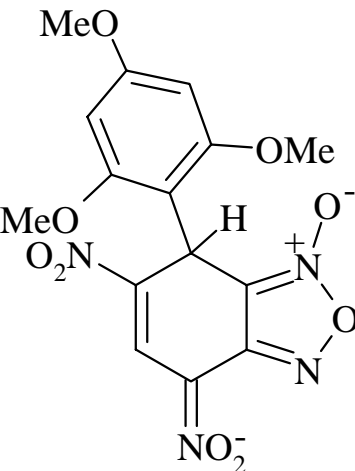

1

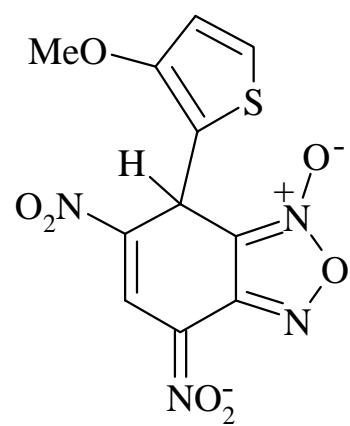

$\underline{2}$

Recently, it has been convincingly recognized that the exceptional electrophilic character of nitrobenzofuroxans is closely related to the low aromaticity of the carbocyclic ring. Crucial evidence for this relationship has been the discovery that the nitro-activated double bonds of this ring behave similarly to nitroalkene fragments in a variety of Diels-Alder processes, acting as dienophiles or heterodienes depending upon the reaction partner and the experimental conditions at hand. ${ }^{11,12}$ A first illustrative sequence refers to the reaction of DNBF with cyclopentadiene. As shown in Scheme 1, it leads to the competitive initial formation of the monoadducts $\mathbf{3}$ and $\mathbf{4}$ (in their racemic forms). ${ }^{13}$ This is followed by the stereoselective formation of the highly functionalized diadduct $\mathbf{5}$ which is eventually obtained and isolated in high yield. ${ }^{13}$ In as much as the $\mathrm{C}_{6}-\mathrm{C}_{7}$ double bond of DNBF is involved in the two initial normal and inverse electron- 
demand Diels-Alder processes, the formation of the NEDDA and IEDDA adducts $\mathbf{3}$ and $\mathbf{4}$ is a clear-cut example of the potentially ambident nitroalkene Diels-Alder reactivity of DNBF. On the other hand, the preferred formation of the unsymmetrical IEDDA-NEDDA adduct $\mathbf{5}$ implies a greater dienophilic reactivity of the remaining nitroolefinic moiety in the IEDDA adduct $\mathbf{4}$ than in the NEDDA adduct 3 . $^{14}$

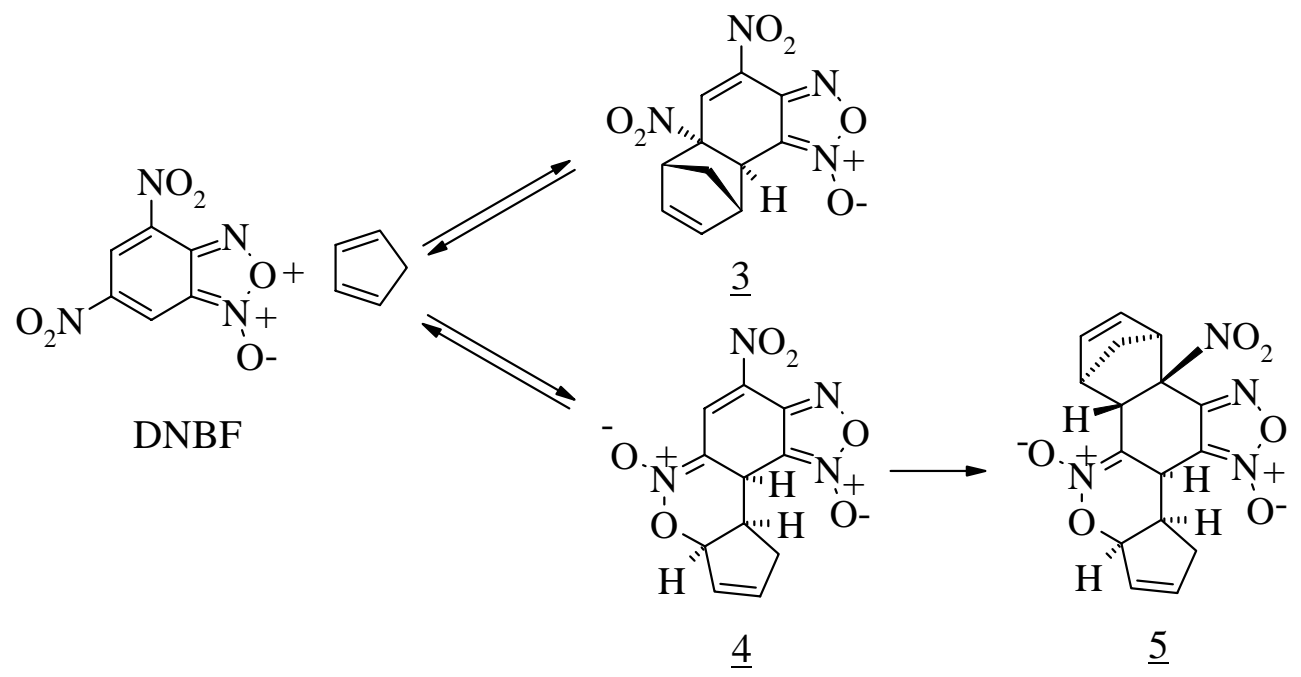

\section{Scheme 1}

A second significant example of the versatile pericyclic reactivity of DNBF is shown in Scheme 2. As can be seen, the reaction of this compound with 1-trimethylsilyloxybuta-1,3-diene 6 gives rise quantitatively to the monoadduct 7 in its racemic form, resulting from a regioselective and diastereoselective NEDDA process involving the $\mathrm{C}_{6}-\mathrm{C}_{7}$ double bond of DNBF as the dienophile contributor. ${ }^{15}$ Interestingly, 7 was inert to further reaction with 6 but not with vinyl ethyl ether. In this instance, the dihydrooxazine $\mathrm{N}$-oxide $\mathbf{8}$ was obtained in $92 \%$ yield, arising from a highly diastereoselective IEDDA condensation involving the $\mathrm{O}_{4} \mathrm{~N}_{4} \mathrm{C}_{4} \mathrm{C}_{5}$ fragment of $\mathbf{7}$ as the heterodiene contributor. The stereochemistry of $\mathbf{8}$, which is overall the result of an "unsymmetrical" NEDDA- IEDDA reactivity sequence, was firmly attributed, as that of the IEDDA-NEDDA diadduct 5 in Scheme 1, by X-ray crystallography. ${ }^{15}$

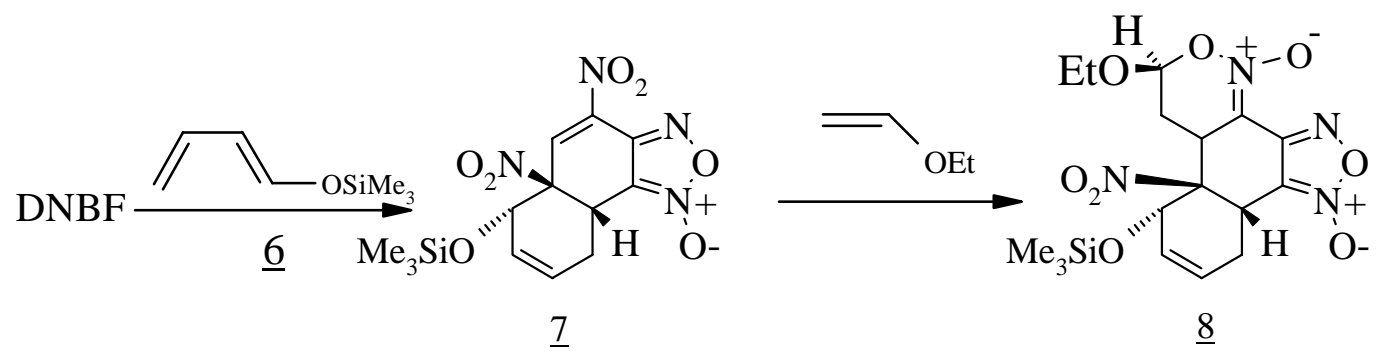

\section{Scheme 2}


As a continuation of our exploration of how the dienophile or heterodiene behaviour of DNBF and related heterocycles can be modulated by changes in the opposed electron-rich substrate, we report here on the results of a detailed study of the reactions of DNBF with isoprene and 2,3-dimethylbutadiene under various experimental conditions. As will be seen, this work has revealed that the complete formation of the thermodynamically more stable products of the interactions, namely the "symmetrical" NEDDA-NEDDA diadducts 11a-b and 12a-b, is in all cases preceded by that of mono- and di- adducts deriving from a variety of NEDDA and IEDDA reaction pathways. Altogether, the results obtained are very illustrative of the multifaceted pericyclic reactivity of nitroactivated 2,1,3-benzoxadiazoles. Also, and for the first time, our investigations have been extended to 4,6-dinitrobenzofurazan (DNBZ), the deoxygenated analogue of DNBF.

\section{Results}

Treatment of DNBF with a large excess of isoprene (10 equiv.) in dichloromethane at room temperature for 2 days afforded two compounds in a 1/1 ratio (overall yield 90\%) which were readily separated by taking advantage of their different solubilities in pentane (Scheme 3). As shown by the ORTEP view of Figure 1, one of these compounds corresponds to a diadduct which is only formed as the diastereomer 11a in its racemic form (only one enantiomer is shown in Scheme 3). Interestingly, the second compound is identical to the diadduct 10a (in its racemic form) that we have previously isolated and structurally characterized as the only product available after running the reaction for an extended period of time (several days). ${ }^{16}$

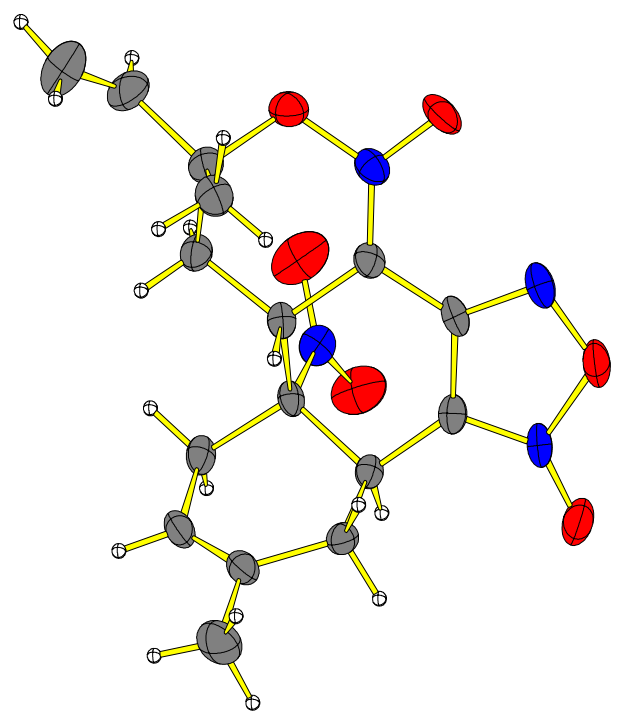

Figure 1. ORTEP view of 11a. 
The stereochemistry of 11a in the crystal agrees well with the structural information provided by a detailed analysis of the ${ }^{1} \mathrm{H}$ and ${ }^{13} \mathrm{C}$ NMR spectra recorded in $\mathrm{CDCl}_{3}$ via COSY and HETCOR, as well as J-modulation experiments. Among other notable diagnostic features for 11a, there is the observation that the disappearance of the low field proton and carbon resonances associated with the $\mathrm{C}_{4} \mathrm{C}_{5} \mathrm{C}_{6} \mathrm{C}_{7}$ fragment of the DNBF structure goes along with a strong deshielding of the two $\mathrm{sp}^{3}$ carbons $\mathrm{C}_{6}$ and $\mathrm{C}_{15}$. Both benefit from the strong electronwithdrawing inductive effect exerted by a $\mathrm{NO}_{2}$ group and a $\mathrm{O}-\mathrm{N}^{+}-\mathrm{O}^{-}$fragment of a dihydrooxazine $\mathrm{N}$-oxide ring. Also typical is the presence of the three vinylic protons $\mathrm{H}_{16}, \mathrm{H}_{17 a}$ and $\mathrm{H}_{17 \mathrm{~b}}$ at 5.97, 5.45 and $5.35 \mathrm{ppm}$, respectively, in the ${ }^{1} \mathrm{H}$ spectra (see Table 2). NOE experiments have revealed the close space proximity of the protons $\mathrm{H}_{5}$ and $\mathrm{H}_{14 \mathrm{~b}}$ as well as of $\mathrm{H}_{7}$ and $\mathrm{H}_{10 \mathrm{~b}}$.

Despite its remarkable stability in the solid state, the diadduct 11a is not the thermodynamically stable product of the reaction of DNBF with isoprene. Major changes in the ${ }^{1} \mathrm{H}$ and ${ }^{13} \mathrm{C}$ spectra occurred with time when a $\mathrm{CDCl}_{3}$ solution of $\mathbf{1 1 a}$ is kept at room temperature, with in about a month, an essentially complete disappearance of the resonances due to 11a and a concomitant development of new sets of proton or carbon signals ascribable to 10a. At completion of the interconversion, the recorded ${ }^{1} \mathrm{H}$ and ${ }^{13} \mathrm{C}$ spectra were in fact totally identical to those obtained after dissolution of a few crystals of $\mathbf{1 0 a}$ in the same solvent. ${ }^{16}$

A similar reactivity pattern was found to prevail in the interaction of DNBF with 2,3dimethylbutadiene and of DNBZ with isoprene and 2,3-dimethylbutadiene with a competitive formation of the adducts $11 \mathbf{b}$ and $10 b$ or $11 \mathbf{c}-\mathbf{d}$ and $10 \mathbf{c}-\mathbf{d}$ in the early stages of the reactions. In these instances, however, the diadducts $\mathbf{1 1} \mathbf{c}-\mathbf{d}$ and $\mathbf{1 1 b}$ could not be isolated as pure crystalline solids due to a relatively fast conversion into the stable isomers $\mathbf{1 0 c - d}$ and $\mathbf{1 0 b}$. In fact, 11c-d and 11b could be characterized through their ${ }^{1} \mathrm{H}$ NMR spectra, which are closely similar to that of 11a. The whole ${ }^{1} \mathrm{H}$ and ${ }^{13} \mathrm{C}$ NMR data for all characterized diadducts are collected in Tables 1-4. ( see pp 98-100)

In accordance with its greater olefinic character, the $\mathrm{C}_{6}-\mathrm{C}_{7}$ double bond of DNBF has been found to be more reactive than its $\mathrm{C}_{4}-\mathrm{C}_{5}$ counterpart in all Diels-Alder condensation pathways so far studied. Based on this, one could anticipate that the diadducts 10a-d and 11a-d are the result of competitive inverse and normal electron-demand reactions involving the remaining nitroalkene-like $\mathrm{C}_{4}-\mathrm{C}_{5}$ fragment of an initially formed NEDDA monoadduct of type 9a-d. 


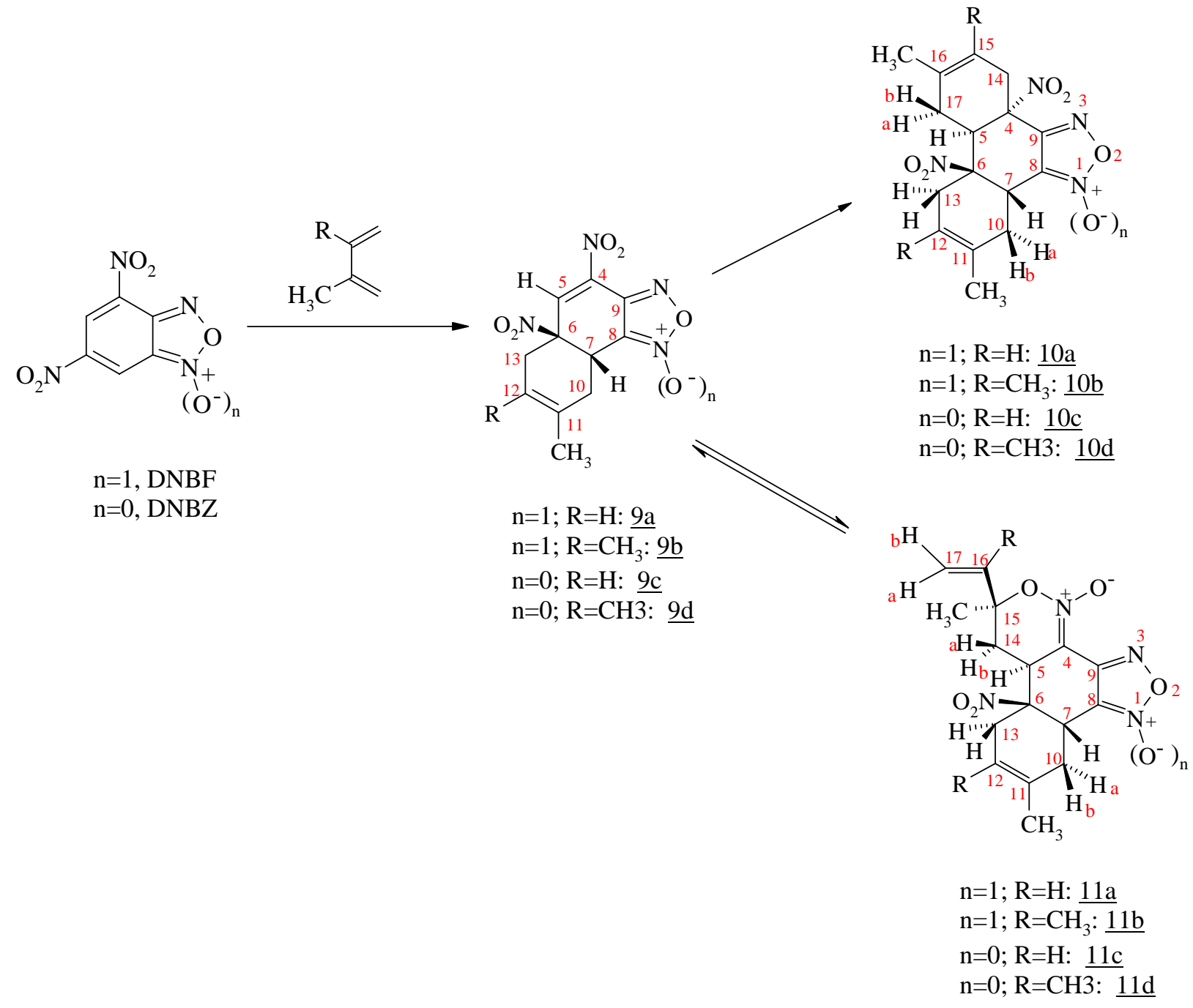

\section{Scheme 3}

Confirmation of the reactivity sequence proposed in Scheme 3 could in fact be obtained through experiments carried out with equimolar amounts of the reagents, i.e. DNBF with isoprene or 2,3-dimethylbutadiene. In these two systems, the ${ }^{1} \mathrm{H}$ and ${ }^{13} \mathrm{C}$ NMR spectra recorded a few minutes after mixing of the reagents revealed the appearance of new sets of signals consistent with the formation of the adducts 9a-b (Tables 1 and 3). Importantly, the regioselectivity of the condensation could be unambiguously established through ${ }^{15} \mathrm{~N}$ labelling of the $4-\mathrm{NO}_{2}$ group of DNBF. In this case, the only low-field proton observed in the ${ }^{1} \mathrm{H}$ NMR spectra of 9a-b is found to be coupled with the ${ }^{15} \mathrm{~N}$ atom $\left({ }^{3} \mathrm{~J}_{\mathrm{N} 4 \mathrm{H} 5} \sim 3 \mathrm{~Hz}\right)$, leaving no doubt that this proton is $\mathrm{H}_{5} \cdot{ }^{17}$ In contrast, the cis-stereochemistry of $\mathbf{9 a - b}$ could not be firmly defined on the basis of the collected NMR data. However, 9a and $\mathbf{9 b}$ are obviously the only structures which can be viewed as the precursors of the related diadducts $10 \mathbf{a}-\mathbf{b}$ and $\mathbf{1 1 a} \mathbf{a}-\mathbf{b}$. 
Table 1. ${ }^{1} \mathrm{H}$ NMR data for the monoadducts 9 a-d $\left(\mathrm{CDCl}_{3}\right)$

\begin{tabular}{|c|c|c|c|c|c|c|c|c|c|c|c|}
\hline $9 a$ & 7.57 & 4.22 & $\begin{array}{l}2.67(\mathrm{a}) \\
2.32(\mathrm{~b})\end{array}$ & 5.49 & $\begin{array}{l}3.14(\mathrm{a}) \\
2.81(\mathrm{~b})\end{array}$ & - & - & - & - & 1.76 & $\begin{array}{c}{ }^{3} \mathrm{~J}_{7 / 10 \mathrm{a}, \mathrm{b}}=7.2 ;{ }^{2} \mathrm{~J}_{10 \mathrm{a} / 10 \mathrm{~b}} \approx 19.0 ; \\
{ }^{2} \mathrm{~J}_{13 \mathrm{a} / 13 \mathrm{~b}}=18.80\end{array}$ \\
\hline $9 b$ & 7.54 & 4.15 & $\begin{array}{l}2.66(\mathrm{a}) \\
2.28(\mathrm{~b})\end{array}$ & - & $\begin{array}{l}3.09(\mathrm{a}) \\
2.71(\mathrm{~b})\end{array}$ & - & - & - & - & $\begin{array}{l}1.75 \\
1.70\end{array}$ & $\begin{array}{c}{ }^{3} \mathrm{~J}_{7 / 10 \mathrm{a}, \mathrm{b}}=7.2 ;{ }^{2} \mathrm{~J}_{10 \mathrm{a} / 10 \mathrm{~b}} \approx 17.7 ; \\
{ }^{2} \mathrm{~J}_{13 \mathrm{a} / 13 \mathrm{~b}}=17.4\end{array}$ \\
\hline $9 c$ & 7.71 & 4.39 & $\begin{array}{l}2.76(\mathrm{a}) \\
2.41(\mathrm{~b})\end{array}$ & 5.44 & $\begin{array}{l}3.16(\mathrm{a}) \\
2.61(\mathrm{~b})\end{array}$ & - & - & - & - & 1.77 & $\begin{array}{c}{ }^{3} \mathrm{~J}_{7 / 10 \mathrm{a}, \mathrm{b}}=6.6 ;{ }^{2} \mathrm{~J}_{10 \mathrm{a} / 10 \mathrm{~b}} \approx 17.0 ; \\
{ }^{2} \mathrm{~J}_{13 \mathrm{a} / 13 \mathrm{~b}}=18.80\end{array}$ \\
\hline
\end{tabular}




\begin{tabular}{|c|c|c|c|c|c|c|c|c|c|c|c|}
\hline Compounds & $\mathbf{H}_{5}$ & $\mathbf{H}_{7}$ & $\mathbf{H}_{10}$ & $\mathbf{H}_{12}$ & $\mathbf{H}_{13}$ & $\mathrm{H}_{14}$ & $\mathbf{H}_{15}$ & $\mathbf{H}_{16}$ & $\mathbf{H}_{17}$ & $\mathrm{CH}_{3}$ & Coupling constants $(\mathrm{Hz})$ \\
\hline $10 \mathrm{a}$ & 3.90 & 4.19 & $\begin{array}{l}2.76(a) \\
2.45(b)\end{array}$ & 5.34 & $\begin{array}{l}2.85 \text { (a) } \\
2.41(\mathrm{~b})\end{array}$ & 3.21 & 5.43 & - & $\begin{array}{l}2.15(\mathrm{a}) \\
1.93(\mathrm{~b})\end{array}$ & $\begin{array}{l}1.71(11) \\
1.66(16)\end{array}$ & $\begin{array}{c}{ }^{3} \mathrm{~J}_{5 / 17 \mathrm{a}, \mathrm{b}}=8.2 ;{ }^{3} \mathrm{~J}_{7 / 10 \mathrm{a}, \mathrm{b}}=7.9 ;{ }^{2} \mathrm{~J}_{10 \mathrm{a} / 10 \mathrm{~b}}= \\
17.7 ;{ }^{2} \mathrm{~J}_{13 \mathrm{a} / 13 \mathrm{~b}}=16.6 ;{ }^{2} \mathrm{~J}_{17 \mathrm{a} / 17 \mathrm{~b}}=17.9\end{array}$ \\
\hline $10 \mathrm{~b}$ & 3.78 & 4.19 & $\begin{array}{l}2.73(a) \\
2.34(b)\end{array}$ & - & $\begin{array}{l}2.78 \text { (a) } \\
2.27 \text { (b) }\end{array}$ & 3.14 & - & - & $\begin{array}{l}2.08(\mathrm{a}) \\
1.85(\mathrm{~b})\end{array}$ & $\begin{array}{l}1.67 ; 1.65 \\
1.60 ; 1.56\end{array}$ & $\begin{array}{c}{ }^{3} \mathrm{~J}_{5 / 7}=1.1 ;{ }^{3} \mathrm{~J}_{5 / 17 \mathrm{a}, \mathrm{b}}=8.5 ;{ }^{3} \mathrm{~J}_{7 / 10 \mathrm{a}, \mathrm{b}}=7.7 ; \\
{ }^{2} \mathrm{~J}_{10 \mathrm{a} / 10 \mathrm{~b}} \approx 16.5 ;{ }^{2} \mathrm{~J}_{13 \mathrm{a} / 13 \mathrm{~b}}=15.6 ; \\
{ }^{2} \mathrm{~J}_{17 \mathrm{a} / 17 \mathrm{~b}}=17.4\end{array}$ \\
\hline $10 \mathrm{c}$ & 3.97 & 4.14 & $\begin{array}{l}2.88(a) \\
2.67(b)\end{array}$ & 5.23 & $\begin{array}{l}2.88(\mathrm{a}) \\
2.31(\mathrm{~b})\end{array}$ & $\begin{array}{l}3.22(\mathrm{a}) \\
3.02(\mathrm{~b})\end{array}$ & 5.39 & - & $\begin{array}{l}2.23(\mathrm{a}) \\
2.03(\mathrm{~b})\end{array}$ & 1.66 & $\begin{array}{c}{ }^{3} \mathrm{~J}_{5 / 17 \mathrm{a}, \mathrm{b}}=(8.2 ; 7.0) ;{ }^{3} \mathrm{~J}_{7 / 10 \mathrm{a}, \mathrm{b}}=(7.8 ; 4.7) ; \\
{ }^{2} \mathrm{~J}_{10 \mathrm{a} / 10 \mathrm{~b}}=17.1 ;{ }^{2} \mathrm{~J}_{13 \mathrm{a} / 13 \mathrm{~b}}=17.0 ;{ }^{2} \mathrm{~J}_{14 \mathrm{a} / 14 \mathrm{~b}}= \\
15.0 ;{ }^{3} \mathrm{~J}_{17 \mathrm{~b} / 17 \mathrm{a}}=16.2 ;{ }^{3} \mathrm{~J}_{16 / 17 \mathrm{~b}}=10.9\end{array}$ \\
\hline 10d & 3.89 & 4.07 & $\begin{array}{l}2.85(a) \\
2.65(b)\end{array}$ & - & $\begin{array}{l}2.79(\mathrm{a}) \\
2.23(\mathrm{~b})\end{array}$ & $\begin{array}{l}3.21 \text { (a) } \\
2.99 \text { (b) }\end{array}$ & - & - & $\begin{array}{l}2.26(\mathrm{a}) \\
1.95(\mathrm{~b})\end{array}$ & $\begin{array}{c}1.62(3 \\
\left.\mathrm{CH}_{3}\right) \\
1.56\end{array}$ & $\begin{array}{c}{ }^{2} \mathrm{~J}_{10 \mathrm{a} / 10 \mathrm{~b}} \approx 17.1 ;{ }^{2} \mathrm{~J}_{13 \mathrm{a} / 13 \mathrm{~b}}=17.0 ;{ }^{2} \mathrm{~J}_{14 \mathrm{a} / 14 \mathrm{~b}}=15.0 ; \\
{ }^{2} \mathrm{~J}_{17 \mathrm{a} / 17 \mathrm{~b}}=16.2 ;{ }^{3} \mathrm{~J}_{5 / 17 \mathrm{a}}=8.2 ;{ }^{3} \mathrm{~J}_{5 / 17 \mathrm{~b}}=6.9 ; \\
{ }^{3} \mathrm{~J}_{7 / 10 \mathrm{a}}=7.8 ;{ }^{3} \mathrm{~J}_{7 / 10 \mathrm{~b}}=4.7\end{array}$ \\
\hline $11 \mathrm{a}$ & 3.43 & 3.93 & $\begin{array}{l}2.90(a) \\
2.10(b)\end{array}$ & 5.46 & 2.90 & $\begin{array}{l}2.10(a) \\
2.50(b)\end{array}$ & - & 5.97 & $\begin{array}{l}5.47(\mathrm{a}) \\
5.35(\mathrm{~b})\end{array}$ & $\begin{array}{l}1.75(11) \\
1.59(15)\end{array}$ & $\begin{array}{c}{ }^{3} \mathrm{~J}_{5 / 14 \mathrm{a}, \mathrm{b}}=(11.0 ; 7.0) ;{ }^{3} \mathrm{~J}_{7 / 10 \mathrm{a}, \mathrm{b}}=(10.1 ; \\
7.5) ;{ }^{2} \mathrm{~J}_{10 \mathrm{a} / 10 \mathrm{~b}}=17.8 ;{ }^{2} \mathrm{~J}_{13 \mathrm{a} / 13 \mathrm{~b}}=18.0 ; \\
{ }^{2} \mathrm{~J}_{14 \mathrm{a} / 14 \mathrm{~b}}=13.1 ;{ }^{3} \mathrm{~J}_{16 / 17 \mathrm{a}}=17.4\end{array}$ \\
\hline $11 b$ & 3.36 & 3.89 & $\begin{array}{l}2.88(a) \\
2.08(b)\end{array}$ & - & $\begin{array}{l}3.00 \\
2.92\end{array}$ & $\begin{array}{l}1.98 \text { (a) } \\
2.53(\mathrm{~b})\end{array}$ & - & - & $\begin{array}{l}5.19 \\
5.08\end{array}$ & $\begin{array}{l}1.90(16) ; \\
1.75(11) \\
1.70(12) ; \\
1.59(15)\end{array}$ & $\begin{array}{c}{ }^{3} \mathrm{~J}_{5 / 14 \mathrm{a}, \mathrm{b}}=(11.5 ; 6.6) ;{ }^{3} \mathrm{~J}_{7 / 10 \mathrm{a}, \mathrm{b}}=(10.2 ; \\
7.6) ;{ }^{2} \mathrm{~J}_{13 \mathrm{a} / 1 \mathrm{bb}}=18.0 ;{ }^{2} \mathrm{~J}_{14 \mathrm{a} / 14 \mathrm{~b}}=13.1 ; \\
{ }^{3} \mathrm{~J}_{14 \mathrm{a} / \mathrm{HS}}=6.6,{ }^{3} \mathrm{~J}_{17 / \mathrm{CH} 3}=1.3\end{array}$ \\
\hline $11 \mathrm{c}$ & 3.49 & 3.99 & $\begin{array}{l}2.85(a) \\
2.07(b)\end{array}$ & 5.25 & $\begin{array}{l}2.97(\mathrm{a}) \\
2.80(\mathrm{~b})\end{array}$ & $\begin{array}{l}2.10 \text { (a) } \\
2.45 \text { (b) }\end{array}$ & - & 5.98 & $\begin{array}{l}5.44(\mathrm{a}) \\
5.32(\mathrm{~b})\end{array}$ & $\begin{array}{l}1.77(11) \\
1.58(15)\end{array}$ & $\begin{array}{c}{ }^{3} \mathrm{~J}_{5 / 14 a, b}=(11.3 ; 7.1) ;{ }^{3} J_{7 / 10 a, b}=(8.5 ; \\
7.0) ;{ }^{2} J_{10 a / 10 b}=16.5 ;{ }^{2} J_{13 a / 13 b}=17.5 ; \\
{ }^{2} J_{14 a / 14 b}=12.9 ;{ }^{3} J_{16 / 17 a}=17.7 ; \\
{ }^{3} J_{16 / 17 b}=11.0 ;{ }^{3} \mathrm{~J}_{14 a / H 5}=6.6\end{array}$ \\
\hline 11d & 3.43 & 3.87 & $\begin{array}{l}2.91(a) \\
2.11(b)\end{array}$ & - & $\begin{array}{l}3.05 \\
2.84\end{array}$ & $\begin{array}{l}2.02(a) \\
2.55(b)\end{array}$ & - & - & $\begin{array}{c}5.19 ; \\
5.03\end{array}$ & 1.89 & $\begin{array}{c}{ }^{3} \mathrm{~J}_{5 / 14 \mathrm{a}, \mathrm{b}}=(11.8 ; 6.7) ;{ }^{3} \mathrm{~J}_{7 / 10 \mathrm{a}, \mathrm{b}}=(10.0 ; \\
7.8) ;{ }^{2} \mathrm{~J}_{13 \mathrm{a} / 13 \mathrm{~b}}=19.0 ;{ }^{2} \mathrm{~J}_{14 \mathrm{a} / 14 \mathrm{~b}}=13.0 ; \\
{ }^{3} \mathrm{~J}_{14 \mathrm{a} / \mathrm{H} 5}=7.0\end{array}$ \\
\hline
\end{tabular}


Table 3. ${ }^{13} \mathrm{C}$ NMR data for the monoadducts $9 a-d\left(\mathrm{CDCl}_{3}\right)$

\begin{tabular}{cccccccccccccccc}
\hline Compounds & $\mathbf{C}_{\mathbf{4}}$ & $\mathbf{C}_{\mathbf{5}}$ & $\mathbf{C}_{\mathbf{6}}$ & $\mathbf{C}_{\mathbf{7}}$ & $\mathbf{C}_{\mathbf{8}}$ & $\mathbf{C}_{\mathbf{9}}$ & $\mathbf{C}_{\mathbf{1 0}}$ & $\mathbf{C}_{\mathbf{1 1}}$ & $\mathbf{C}_{\mathbf{1 2}}$ & $\mathbf{C}_{\mathbf{1 3}}$ & $\mathbf{C}_{\mathbf{1 4}}$ & $\mathbf{C}_{\mathbf{1 5}}$ & $\mathbf{C}_{\mathbf{1 6}}$ & $\mathbf{C}_{\mathbf{1 7}}$ & $\mathbf{C H}_{\mathbf{3}}$ \\
\hline $\mathbf{9 a}$ & 141.13 & 137.64 & 87.32 & 33.08 & 109.72 & 143.50 & 29.06 & 134.39 & 115.50 & 34.64 & - & - & - & - & 22.56 \\
$\mathbf{9 b}$ & 141.06 & 137.29 & 88.25 & 33.17 & 109.88 & 143.39 & 30.59 & 126.50 & 121.60 & 40.10 & - & - & - & - & $18.84(12)$ \\
& & & & & & & & & & & $18.33(11)$ \\
$\mathbf{9 c}$ & 142.01 & 137.98 & 88.78 & 33.37 & 153.35 & 143.34 & 32.04 & 125.53 & 121.05 & 39.09 & - & - & - & - & $18.85(12)$ \\
$9 \mathbf{9 d}$ & 143.22 & 138.45 & 88.02 & 33.29 & 154.27 & 144.23 & 30.24 & 133.82 & 115.15 & 34.64 & - & - & - & - & 22.81 \\
\hline
\end{tabular}

Table 4. ${ }^{13} \mathrm{C}$ NMR data for the Diadducts $10 a-b$ and 11a and $11 \mathrm{c}\left(\mathrm{CDCl}_{3}\right)$

\begin{tabular}{|c|c|c|c|c|c|c|c|c|c|c|c|c|c|c|c|}
\hline Compounds & $\mathrm{C}_{4}$ & $\mathrm{C}_{5}$ & $\mathrm{C}_{6}$ & $\mathbf{C}_{7}$ & $\mathbf{C}_{8}$ & $\mathrm{C}_{9}$ & $\mathrm{C}_{10}$ & $\mathrm{C}_{11}$ & $\mathrm{C}_{12}$ & $\mathrm{C}_{13}$ & $\mathrm{C}_{14}$ & $\mathrm{C}_{15}$ & $\mathrm{C}_{16}$ & $\mathrm{C}_{17}$ & $\mathrm{CH}_{3}$ \\
\hline $10 \mathrm{a}$ & 86.26 & 42.23 & 92.56 & 30.64 & 112.33 & 149.65 & 28.13 & 135.03 & 116.35 & 32.20 & 33.51 & 115.93 & 131.72 & 28.55 & $\begin{array}{l}22.27(11) \\
22.62(16)\end{array}$ \\
\hline & & & & & & & & & & & & & & & $18.59(12)$ \\
\hline $10 \mathrm{~b}$ & 86.80 & 43.49 & 93.95 & 30.37 & 112.40 & 149.50 & 29.38 & 126.24 & 123.22 & 37.96 & 38.87 & 121.98 & 123.22 & 30.54 & $18.27(16,11)$ \\
\hline & & & & & & & & & & & & & & & $18.12(15)$ \\
\hline $10 \mathrm{c}$ & 85.98 & 41.99 & 91.33 & 30.94 & 153.69 & 148.12 & 32.37 & 133.46 & 115,36 & 31.13 & 35.72 & 116.32 & 133.52 & 27.60 & 22.29 (11) \\
\hline & & & & & & & & & & & & & & & 22.47 (16) \\
\hline 10d & 86.64 & 43.29 & 92.43 & 30.81 & 153.94 & 148.16 & 33.43 & 125.30 & 124.88 & 36.83 & 41.79 & 121.33 & 123.35 & 29.68 & $\begin{array}{c}18.90 ; 18.45 \text {; } \\
18.17\end{array}$ \\
\hline 11a & 10831 & 3408 & 8479 & 3399 & 11227 & 14561 & 3218 & 13200 & 11573 & 3150 & 3012 & 8805 & 13796 & 11708 & $22.18(11)$ \\
\hline & & & & & & & & & & & & & & & 22.56 (15) \\
\hline $11 \mathrm{c}$ & 109.12 & 35.12 & 85.45 & 34.45 & 152.78 & 148.19 & 34.08 & 132.24 & 115.45 & 31.77 & 30.23 & 88.74 & 138.19 & 116.70 & 22.27(11) \\
\hline
\end{tabular}


Also, it is noteworthy that $\mathrm{X}$-ray crystallography evidence for a cis-junction was previously obtained in the case of the adduct 7 of DNBF and 1-trimethylsilyloxybuta-1,3-diene as well as the adduct 12 of 4-aza-6-nitrobenzofuroxan and 2,3-dimethylbutadiene. That $\mathrm{H}_{7}$ and the 6- $\mathrm{NO}_{2}$ group lie on the same side of the two six-membered rings is also the situation encountered in the DNBF-cylopentadiene monoadduct 3 . $^{11 b, 15 b}$

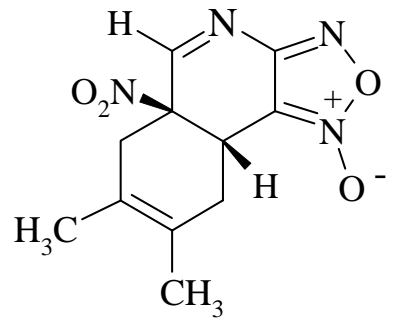

$\underline{12}$

The overall conversion of the reagents into the thermodynamically stable diadducts of type 10a-d being faster in the DNBZ- than in the DNBF-isoprene or 2,3-dimethylbutadiene systems, it is only in working with an excess of DNBZ (1 eq.) over the diene at hand (0.8 eq.) that we have succeeded in characterizing the transient monoadducts $9 \mathbf{c}$ and $9 \mathbf{d}$ in the early stages of the reactions. Under these experimental conditions, the ${ }^{1} \mathrm{H}$ and ${ }^{13} \mathrm{C}$ NMR spectra recorded immediately after mixing showed in fact the presence of signals typical for the formation of these monoadducts. As can be seen in Tables 1-4, these resonances are closely similar to those identified for the related DNBF adducts $\mathbf{9 a}$ and $\mathbf{9 b}$. The only exception is the resonance for the $\mathrm{C}_{8}$ carbon which is known to be considerably more shielded in benzofuroxan $(\delta=110 \pm 5 \mathrm{ppm})$ than in benzofurazan $(\delta=150 \pm 5 \mathrm{ppm})$ structures. ${ }^{8,11}$

\section{Discussion}

The results obtained in the present study reveal that the interactions of DNBF and DNBZ with isoprene and 2,3-dimethylbutadiene proceed through the initial formation of the monoadducts 9a-d, resulting from a regioselective NEDDA process involving the nitroactivated $\mathrm{C}_{6}-\mathrm{C}_{7}$ double bonds of the parent heterocycles as the dienophile contributors. The observed regioselectivity being consistent with the afore-mentioned greater olefinic character of this bond, a more noteworthy feature is the high stereospecificity of the reactions which give rise exclusively to the adducts 9a-d with the 6- $\mathrm{NO}_{2}$ group and $\mathrm{H}_{7}$ being on the same side of the two rings. This further adds to the evidence that this diastereospecificity is a general rule in the formation of NEDDA adducts of nitrobenzoxadiazoles compounds.

In contrast with the situation observed in the DNBF- cyclopentadiene system (Scheme 1), no evidence for an initial competitive formation of the IEDDA monoadducts 13a-d could be obtained. The formation of 9a-d is apparently both kinetically and thermodynamically favored 
relative to 13a-d in the systems described in Scheme 3. This opens the route to a second condensation an isoprene or 2,3-dimethylbutadiene molecule at the remaining nitroactivated $\mathrm{C}_{4}$ $\mathrm{C}_{5}$ fragment of 9a-d which appears to react both as a heterodienic moiety to afford the NEDDAIEDDA diadducts 11a-d and a dienophile to afford the NEDDA-NEDDA diadducts 10a-d.

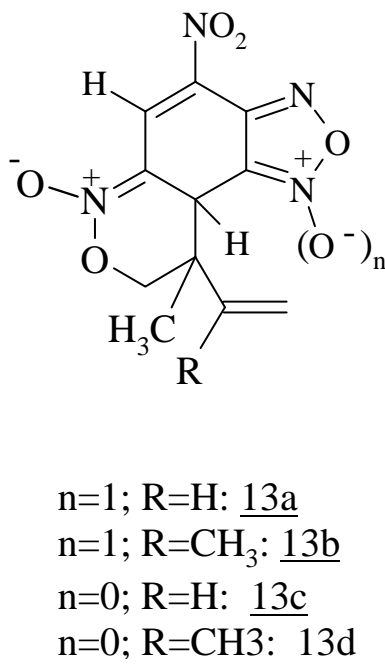

Again, a remarkable feature is the high stereospecificity of the condensations since only the diasteromers shown in Scheme 3 are obtained (only one enantiomer is shown in each case). Because of a more favorable thermodynamic driving force for formation of 10a-d than 11a-d, the complete equilibrium system of Scheme 3 is progressively shifted towards the obtention of the NEDDA-NEDDA diadducts 10a-d. There is little doubt that these species correspond to the products isolated in 1973 by Kresze and Bathelt. ${ }^{17}$ At this time, however, no attempt was made to elucidate the stereochemistry and the mechanistic course of the reactions.

That the addition of the second molecule of isoprene and 2,3-dimethylbutadiene to the monoadducts 9a-d occurs through competitive normal and inverse electron-demand pathways to give a mixture of the NEDDA-NEDDA and NEDDA-IEDDA diadducts 10a-d and 11a-d, respectively, is an unprecedented finding in the chemistry of DNBF. In previous works, the contrasting "unsymmetrical" IEDDA-NEDDA sequence (see Scheme 1) and the two "symmetrical" NEDDA-NEDDA and IEDDA-IEDDA sequences have been observed upon treatment of DNBF with an excess of diene or ethyl vinyl ether. So far, the only known adduct of the NEDDA-IEDDA type was prepared through successive addition of two different reagents, namely 1-trimethylsilyloxybuta-1,3-diene and ethyl vinyl ether (Scheme 2).

Altogether, the present results illustrate the considerable scope of reactivity of nitrobenzofuroxans and nitrobenzofurazans in Diels-Alder processes. Theoretical work is currently carried out to get a better understanding of the various pathways involved in the interactions. 

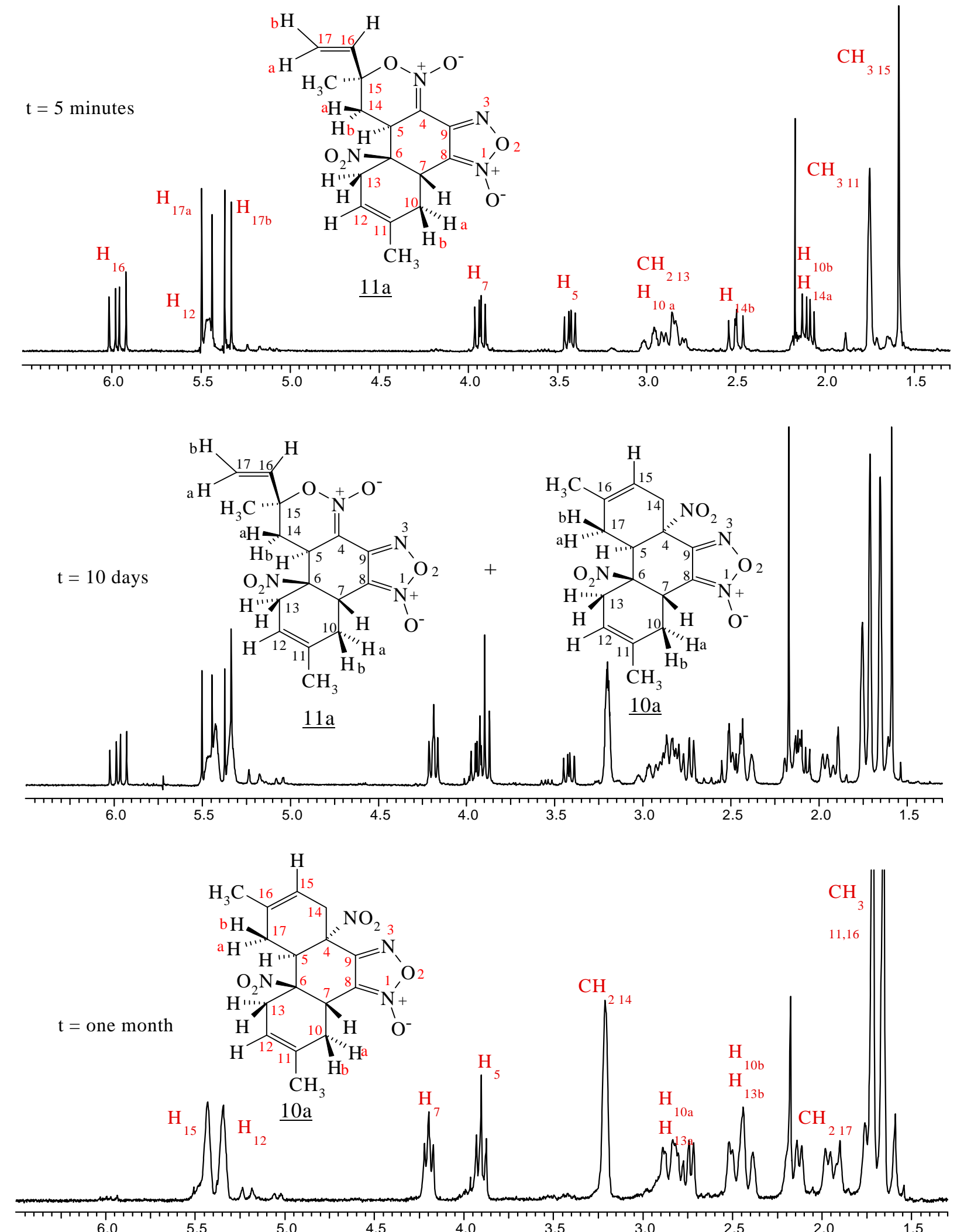

Figure 2. Time dependence of the ${ }^{1} \mathrm{H}$ NMR spectra of a pure sample of $\mathbf{1 1 a}$ in $\mathrm{CDCl}_{3}$. 


\section{Experimental Section}

General Procedures. Melting points were determined on a Reichert-type microscope and are uncorrected. ${ }^{1} \mathrm{H}$ and ${ }^{13} \mathrm{C}$ NMR spectra were recorded on a $300 \mathrm{MHz}$ spectrometer. Chemical shifts are reported in ppm ( $\mathrm{J}$ values in Hertz) relative to internal $\mathrm{Me}_{4} \mathrm{Si}$. Electronic Impact mass spectra (EI, 70eV) were obtained using a HEWLETT PACKARD 5989B and a NERMAG R1010C spectrometer equipped with a quadrupole. Elemental analyses were determined by the Microanalytical Laboratory of the University Paris VI, France. I.R. spectra were recorded on a NICOLET 400D spectrometer. The crystal structure (Figures 1) has been deposited at the Cambridge Crystallographic Data Centre and allocated the deposition number CCDC-222581.

Materials. Commercial 2,3-dimethylbutadiene and isoprene were used without further purification. $\mathbf{D N B F}{ }^{19}$ and $\mathbf{D N B Z}{ }^{2 \mathrm{~b}, 20}$ were prepared according to standard procedures reported by Drost and our laboratory, respectively. DNBF : mp: $173^{\circ} \mathrm{C}$ ( lit.: $172-174{ }^{\circ} \mathrm{C}$ ) $;^{19} \mathrm{DNBZ}: \mathrm{mp}$ : $130^{\circ} \mathrm{C}$ (lit.: $\left.129-132^{\circ} \mathrm{C}\right) .^{2 \mathrm{~b}, 20}$

\section{General procedure for preparation of the Diels-Alder adducts In situ formation of monoadducts}

To a solution of DNBF or DNBZ in $\mathrm{CDCl}_{3}$ was added 0.8 eq. to 1 eq. of isoprene or 2,3dimethylbutadiene. ${ }^{1} \mathrm{H}$ NMR spectra were recorded just after mixing the reagents, allowing the signals of the monoadducts to be detected. Subsequent addition of a second equivalent of diene resulted in the formation of a mixture of the diadducts 10a-d and 11a-d and after a few days the recorded ${ }^{1} \mathrm{H}$ and ${ }^{13} \mathrm{C}$ spectra were totally identical to those obtained after dissolution of the isolated and thermodynamically stable diadducts 10a-d.

\section{Formation of diadducts}

Reaction of isoprene with DNBF. To a solution of DNBF (1g.) in $\mathrm{CH}_{2} \mathrm{Cl}_{2}(10 \mathrm{ml})$ at room temperature was added an excess (10 equiv.) of isoprene. The solution turned rapidly to orange and the reaction mixture was stirred at room temperature for two days. Addition of pentane resulted in the immediate formation of a precipitate which was collected by filtration and dried under vacuum and then purified by column chromatography, using pentane-ethylacetate mixtures as eluents. The evidence is that this isolated compound is 11a. Evaporation of the mother liquor led to the isolation of a white solid which was characterized without further purification and identified as 10c. Longer reaction times (four to five days) led to the exclusive formation of the NEDDA-NEDDA adduct 10a in a 90\% yield.

Diadduct 10a. white solid; yield 55\%; m. p.: $114-116^{\circ} \mathrm{C}$; MS : (E.I.) $315\left(\mathrm{M}-\mathrm{HNO}_{2}\right)^{+{ }^{*}}, 285$ (M$\left.\mathrm{HNO}_{2}-2 \mathrm{CH}_{3}\right)^{+*}, 270\left(\mathrm{M}-2 \mathrm{NO}_{2}\right)^{+*}, 269\left(\mathrm{M}-\mathrm{HNO}_{2}-\mathrm{NO}_{2}\right)^{+*}$.

I.R. $\left(\mathrm{CHCl}_{3}, \mathrm{~cm}^{-1}\right)$ : 2981, $2920\left(v_{\mathrm{C}-\mathrm{H}}\right), 2360\left(v_{\mathrm{C}=\mathrm{N}-\mathrm{O}}\right), 1632\left(v_{\mathrm{C}=\mathrm{C}}\right), 1571$ ( $\left.v_{\mathrm{NO} 2 \text { as }}\right), 1495,1469$, 1449 ( $\left.\delta_{\mathrm{C}-\mathrm{H} \text { ring }}\right), 1388,1362,1327\left(v_{\mathrm{NO} 2 \mathrm{~s}}\right), 1031$ ( $\left.v_{\mathrm{C}-\mathrm{C} \text { ring }}\right), 863\left(v_{\mathrm{C}-\mathrm{NO} 2}\right)$. 
Anal. Calcd for $\mathrm{C}_{16} \mathrm{H}_{18} \mathrm{~N}_{4} \mathrm{O}_{6}$ : C. 53.04 \%; H. 4.97 \%; N. 15.47 \%; found: C. 53.05 \%; H. 4.94 \%; N. $15.41 \%$.

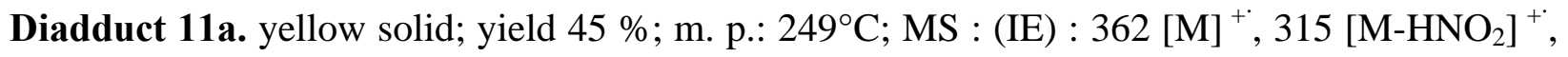
$302[\mathrm{M}-2 \mathrm{NO}]^{+*}, 285\left[\mathrm{M}-\mathrm{HNO}_{2}-2 \mathrm{CH}_{3}\right]^{+*}, 269\left[\mathrm{M}-\mathrm{HNO}_{2}-\mathrm{NO}_{2}\right]^{+*}$.

I.R. $\left(\mathrm{CHCl}_{3}, \mathrm{~cm}^{-1}\right)$ : 3000, $2866\left(v_{\mathrm{C}-\mathrm{H}}\right), 2401\left(v_{\mathrm{C}=\mathrm{N}-\mathrm{O}}\right), 1653\left(v_{\mathrm{C}=\mathrm{C}}\right), 1556,\left(v_{\mathrm{NO} 2}\right.$ as $), 1469$ $\left(\delta_{\mathrm{CH} 2, \mathrm{CH} 3}\right), 1357,1327\left(v_{\mathrm{NO} 2 \mathrm{~s}}\right), 1072\left(v_{\mathrm{C}-\mathrm{C} \text { ring }}\right), 855\left(v_{\mathrm{C}-\mathrm{NO} 2}\right)$.

Anal. Calcd for $\mathrm{C}_{18} \mathrm{H}_{22} \mathrm{~N}_{4} \mathrm{O}_{6}$ : C. 53.04 \%; H. 4.97 \%; N. 15.47 \%; found, C. $52.90 \%$; H. $5.03 \%$; N. $15.28 \%$. Cristallographic data: $\mathrm{C}_{17} \mathrm{H}_{19} \mathrm{Cl}_{3} \mathrm{~N}_{4} \mathrm{O}_{6}, \mathrm{FW}=481.71$ g.mol ${ }^{-1}$, monoclinic, $\mathrm{C} 2, \mathrm{a}=$ 23.3711 $\AA, b=10.0081 \AA, c=9.1700 \AA, \beta=101.74^{\circ}, V=2125.0 \AA^{3}, D c=1.506$ g.cm ${ }^{-3}, Z=4$.

\section{Reaction of 2,3-dimethylbutadiene with DNBF}

The reaction was carried out as above and afforded the diadduct $\mathbf{1 0 b}$ in a $84 \%$ yield. As elaborated in the results section, the isomeric diadduct $11 \mathbf{b}$ could be only characterized in situ by NMR.

Diadduct 10b. white solid; yield $84 \%$; m. p.: $149^{\circ} \mathrm{C}$; MS : (C.I.) $408\left[\mathrm{M}+\mathrm{NH}_{4}\right]^{+}, 361[\mathrm{M}+\mathrm{H}-$ $\left.\mathrm{C}_{2} \mathrm{H}_{6}\right]^{+}$.I.R. $\left(\mathrm{CHCl}_{3}, \mathrm{~cm}^{-1}\right)$ : 2914, $2864\left(v_{\mathrm{C}-\mathrm{H}}\right), 2436,2402\left(v_{\mathrm{C}=\mathrm{N}-\mathrm{O}}\right), 1633\left(v_{\mathrm{C}=\mathrm{C}}\right), 1566,1553$ $\left(v_{\mathrm{NO} 2 \text { as }}\right), 1487,1464,1448\left(\delta_{\mathrm{CH} 2, \mathrm{CH} 3}\right), 1358,1333\left(v_{\mathrm{NO} 2 \mathrm{~s}}\right), 1133,1101$ ( $\left.v_{\mathrm{C}-\mathrm{C} \text { ring }}\right), 876\left(v_{\mathrm{C}-\mathrm{NO} 2}\right)$. Anal. Calcd for $\mathrm{C}_{18} \mathrm{H}_{22} \mathrm{~N}_{4} \mathrm{O}_{6}$ : C. 55.38\%; H. $5.64 \%$; N. 14.36 \%; found: C. 55.25\%; H. $5.68 \%$; N. $14.19 \%$.

\section{Reaction of isoprene or 2,3-dimethylbutadiene with DNBZ}

To a solution of DNBZ (1g.) in $\mathrm{CH}_{2} \mathrm{Cl}_{2}(10 \mathrm{ml})$ at room temperature was added an excess (10 equiv.) isoprene or 2,3-dimethylbutadiene. The solution turned rapidly to orange and the reaction mixture was stirred at room temperature for a few days. Addition of pentane resulted, in each case, in the immediate formation of a precipitate which was collected by filtration and dried under vacuum. Purification of the two precipitates by column chromatography, using pentaneethylacetate mixtures as eluents, afforded the diadducts 10c and 10d in good yields. As for the DNBF / 2,3-dimethylbutadiene system, the isomers $11 \mathbf{c}$ and $11 \mathbf{d}$ were only characterized in situ by NNMR. The whole NMR data are collected in Tables 1-4.

Diadduct 10c. white solid; yield $70 \%$; m. p.: $230^{\circ} \mathrm{C}$; MS : (C.I.) $364\left[\mathrm{M}+\mathrm{NH}_{4}\right]^{+}, 317$ [M+ $\mathrm{NH}_{4}{ }^{-}$ $\left.\mathrm{HNO}_{2}\right]^{+}$.I.R. $\left(\mathrm{CHCl}_{3}, \mathrm{~cm}^{-1}\right): 2920,2859\left(v_{\mathrm{C}-\mathrm{H}}\right), 2430,2409\left(v_{\mathrm{C}=\mathrm{N}-\mathrm{O}}\right), 1601\left(v_{\mathrm{C}=\mathrm{C}}\right), 1566\left(v_{\mathrm{NO} 2 \mathrm{as}}\right)$, $1403\left(\delta_{\mathrm{CH} 2, \mathrm{CH} 3}\right), 1357,1327\left(v_{\mathrm{NO} 2 \mathrm{~s}}\right), 1072\left(v_{\mathrm{C}-\mathrm{C} \text { ring }}\right), 855\left(v_{\mathrm{C}-\mathrm{NO} 2}\right)$.

Anal. Calcd for $\mathrm{C}_{16} \mathrm{H}_{18} \mathrm{~N}_{4} \mathrm{O}_{5}$ : C. 55.49\%; H. $5.20 \%$; N. $16.18 \%$; found: C. 55.55\%; H. $5.25 \%$; N. $16.09 \%$.

Diadduct 10d. white solid; yield $89 \%$; m. p.: $127^{\circ} \mathrm{C}$; MS : (C.I.) $392\left[\mathrm{M}+\mathrm{NH}_{4}\right]^{+}, 361[\mathrm{M}+\mathrm{H}-$ $\left.2 \mathrm{HNO}_{2}\right]^{+}, 345\left[\mathrm{M}+\mathrm{H}_{-} \mathrm{C}_{2} \mathrm{H}_{6}\right]^{+}$. I.R. $\left(\mathrm{CHCl}_{3}, \mathrm{~cm}^{-1}\right): 2916,2862\left(v_{\mathrm{C}-\mathrm{H}}\right), 2434,2401\left(v_{\mathrm{C}=\mathrm{N}-\mathrm{O}}\right), 1628$

$\left(v_{\mathrm{C}=\mathrm{C}}\right), 1562,1553\left(v_{\mathrm{NO} 2 \text { as }}\right), 1448\left(\delta_{\mathrm{CH} 2, \mathrm{CH} 3}\right), 1350,1329\left(v_{\mathrm{NO} 2 \mathrm{~s}}\right), 1135,1099\left(v_{\mathrm{C}-\mathrm{C} \mathrm{ring}}\right), 892$ $\left(v_{\mathrm{C}-\mathrm{NO} 2}\right)$. Anal. Calcd for $\mathrm{C}_{18} \mathrm{H}_{22} \mathrm{~N}_{4} \mathrm{O}_{5}$ : C. 57.75\%; H. $5.88 \%$; N. $14.97 \%$; found: C. 57.55\%; H. $5.75 \%$; N. $15.09 \%$. 


\section{References}

1. (a) Terrier, F. In Nucleophilic Aromatic Displacement; Feuer, H. Ed.; VCH: New York, 1991. (b) Terrier, F Chem. Rev. 1982, 82, 77. (c) Buncel, E.; Dust, J. M.; Terrier, F Chem. Rev. 1995, 95, 2261.

2. (a) Terrier, F; Millot, F.; Norris, W. P. J. Am. Chem. Soc. 1976, 98, 5883. (b) Terrier, F.; Chatrousse, A. P.; Soudais, Y; Hlaibi, M. J. Org. Chem. 1984, 49, 4176. (c) Terrier, F.; Pouet, M. J.; Kizilian, E.; Hallé, J. C.; Outurquin, F.; Paulmier, C. J. Org. Chem. 1993, 58, 4696.

3. (a) Strauss, M. J.; Renfrow, R. A.; Buncel, E. J. Am. Chem. Soc. 1983, 105, 2473. (b) Buncel,

E.; Renfrow, R. A.; Strauss, M. J. J. Org. Chem. 1987, 52, 488. (c) Buncel, E.; Dust, J. M.; Manderville, R. A. J. Am. Chem. Soc. 1996, 118, 6072. (d) Buncel, E.; Manderville, R. A.; Dust, J. M. J. Chem. Soc., Perkin Trans 2 1997, 1019 and references therein.

4. (a) Crampton, M. R.; Rabbitt, L. C. J. Chem. Soc., Perkin Trans 2 1999, 1669. (b) Crampton, M. R.; Rabbitt, L. C.; Terrier, F. Can. J. Chem. 1999, 77, 639. (c) Crampton, M. R.; Rabbitt, L. C. J. Chem. Soc., Perkin Trans 2 2000, 2159. (d) Atherton, J. H.; Crampton, M. R.; Duffield, G. L.; Stevens, J. A. J. Chem. Soc., Perkin Trans 2 1995, 443.

5. (a) Kind, J.; Niclas, H. J. Synth. Commun. 1993, 23, 1569. (b) Niclas, H. J.; Göhrmann, B.; Gründemann Synth. Commun. 1989, 19, 2789.

6. Ghosh, P. B.; Ternai, B.; Whitehouse, M. W. Med. Res. Rev. 1981, 1, 159 and references therein.

7. Evgen'yev, M. I.; Garmonov, S. Y.; Evgen'yeva, M. I.; Gazizullina, L. S. J. Anal. Chem. 1998, 53, 57 and references therein.

8. Lowe-Ma, C. K.; Nissan, R. A.; Wilson, W. S. J. Org. Chem. 1990, 55, 3755.

9. Olekhnovich, L. P.; Budarina, Z. N.; Lesin, A. V.; Kurbatov, S. V.; Borodkin, G. S.; Minkin, V. I. Mendeleev Commun. 1994, 162.

10. (a) Terrier, F.; Kizilian, E.; Hallé, J. C.; Buncel, E. J. Am. Chem. Soc. 1992, 114, 1740. (b) Kizilian, E.; Terrier, F.; Chatrousse, A. P.; Gzouli, K.; Hallé, J. C. J. Chem. Soc. Perkin Trans 2 1997, 2567. (c) Terrier, F.; Pouet, M. J.; Hallé, J. C.; Kizilian, E.; Buncel, E. J. Phys. Org. Chem. 1998, 11, 707. (d) Terrier, F.; Pouet, M. J.; Gzouli, K.; Hallé, J. C.; Outurquin, F.; Paulmier, C. Can. J. Chem. 1998, 76, 937.

11. (a) Sebban, M.; Goumont, R.; Hallé, J. C.; Marrot, J.; Terrier, F. Chem. Commun. 1999, 1009. (b) Terrier, F.; Sebban, M.; Goumont, R.; Hallé, J. C.; Moutiers, G.; Cangelosi, I. Buncel, E.; J. Org. Chem. 2000, 65, 7391. (c) Sepulcri, P.; Goumont, R.; Hallé, J. C.; Riou, D.; Terrier, F. J. Chem. Soc., Perkin Trans. 2 2000, 51. (d) Goumont, R. ; Sebban, M. and Terrier, F. Chem. Commun. 2002, 2110.

12. Pugnaud, S.; Masure, D.; Hallé, J. C.; Chaquin, P. J. Org. Chem. 1997, 62, 8687.

13. Sepulcri, P.; Hallé, J. C.; Goumont, R.; Riou, D.; Terrier, F. J. Org. Chem. 1999, 64, 9254. 
14. For the Diels-Alder reactivity of nitroalkenes, see: (a) Denmark, S. E., Thorarensen, A. Chem. Rev. 1996, 96, 137. (b) Denmark, S. E., Hurd, S. R., Sacha, H. J. J. Org. Chem. 1997, 62, 1675. (c) Denmark, S. E., Dixon, J. A. J. Org. Chem. 1998, 63, 6167, 6178.

15. (a) Hallé, J. C.; Vichard, D.; Pouet, M. J.; Terrier, F. J. Org. Chem. 1997, 62, 7178. (b) Vichard, D.; Hallé, J. C.; Huguet, B.; Pouet, M. J.; Riou, D.; Terrier, F. Chem. Commun. 1998, 791.

16. Goumont, R.; Sebban, M.; Sépulcri, P.; Marrot, J. and Terrier, F. Tetrahedron 2002, 58, 3249.

17. (a) Terrier, F.; Halle, J.C.; MacCormack, P.; Pouet, M.J. Can. J. Chem. 1988, 67, 503. (b) MacCormack, P.; Halle, J.C.; Pouet, M.J.; Terrier, F. J. Org. Chem. 1988, 53, 4407.

18. Kresze, G.; Bathelt, H.; Tetrahedron 1973, 29, 1043.

19. Drost, P. Liebigs Ann. Chem. 1899, 307, 49.

20. Read, R. W.; Spear, R. J.; Norris, W. P. Aust. J. Chem. 1983, 36, 122 